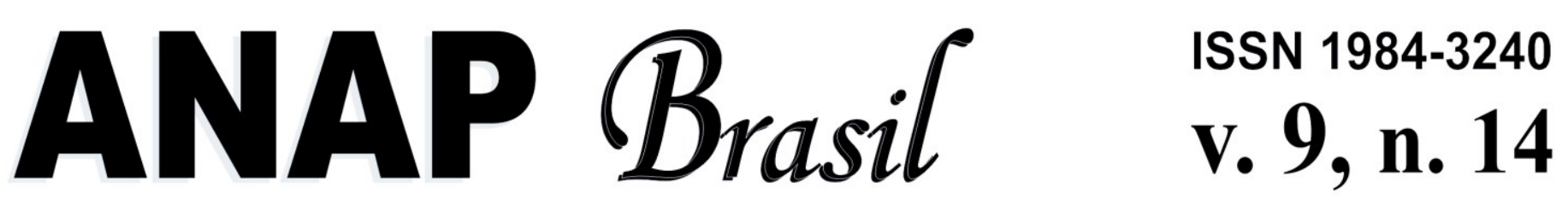

\title{
ARBORIZAÇÃO URBANA E A IMPORTÂNCIA DO PLANEJAMENTO AMBIENTAL ATRAVÉS DE POLÍTICAS PÚBLICAS ${ }^{1}$
}

\author{
AFFORESTATION AND URBAN PLANNING IMPORTANCE OF ENVIRONMENTAL THROUGH PUBLIC \\ POLICY
}

Urban forestación y importancia de la planificación ambiental mediante políticas públicas

\section{Luciano Katsumy Osako² \\ Arquiteto, UNOESTE, Brasil \\ lucianoarquiteto@yahoo.com.br}

Edilene Mayumi Murashita Takenaka ${ }^{3}$

Professora Doutora, UNOESTE, Brasil edilene@unoeste.br

Paulo Antonio da Silva ${ }^{4}$

Professor Doutor, UNOESTE, Brasil. pauloantonio@unoeste.br

\footnotetext{
${ }^{1}$ Artigo produzido na disciplina Meio Ambiente e Economia Solidária-curso Mestrado em Meio Ambiente e Desenvolvimento Regional/Unoeste

${ }^{2}$ Arquiteto, aluno regular - curso Mestrado em Meio Ambiente e Desenvolvimento Regional/Unoeste

${ }^{3}$ Economista, Doutora em Geografia/FCT-Unesp, docente do Mestrado em Meio Ambiente e Desenvolvimento Regional/Unoeste.

${ }^{4}$ Ecólogo, Doutor em Ecologia e Conservação de Recursos Naturais/UFU, docente do Mestrado em Meio Ambiente e Desenvolvimento Regional/Unoeste
} 


\section{RESUMO}

O presente trabalho intitulado "Arborização urbana e a importância do planejamento ambiental através de políticas públicas" teve por objetivo promover reflexões, reforçando a importância da implementação de planejamento ambiental acerca do tema proposto na escala urbanístico municipal e, para seu desenvolvimento fez-se uso da pesquisa bibliográfica. A arborização urbana necessita de um planejamento ambiental correto para que possa trazer benefícios para a ambiência urbana uma vez que, espécies arbóreas nativas devem ter uso preferencial em detrimento de espécies exóticas, pois são mais adaptadas ao ecossistema local e possuem maior resistência e adaptação ao uso urbano do município. Concluiu-se que os benefícios que os elementos arbóreos trazem para o microclima local são consideráveis e, portanto, faz-se necessário fomentar políticas públicas que insiram o planejamento ambiental no Plano Diretor dos municípios.

PALAVRAS-CHAVE: Arborização urbana. Qualidade de vida. Políticas públicas.

\section{ABSTRACT}

This study entitled "Urban Afforestation and the importance of environmental planning through public policies" aimed to promote reflection, reinforcing the importance of the implementation of environmental planning on the proposed theme in the municipal urban scale and to its development made use of bibliographic research. The urban forestry needs a proper environmental planning so you can bring benefits to the urban atmosphere since native tree species should have preferential use to the detriment of exotic species because they are more adapted to the local ecosystem and have greater resistance and adaptation to use urban municipality. It was concluded that the benefits that the arboreal elements bring to the local microclimate are considerable and therefore it is necessary to promote public policies that enter environmental planning in the Master Plan of the municipalities.

KEY WORDS: Afforestation urban. Quality of life. Public Policies.

\section{RESUMEN}

Este estudio titulado "La forestación urbana y la importancia de la planificación del medio ambiente a través de políticas públicas" tiene por objeto promover la reflexión, lo que refuerza la importancia de la aplicación de la planificación ambiental sobre el tema propuesto en la escala urbana municipal y de su desarrollo hecho uso de búsqueda bibliográfica. La silvicultura urbana necesita una planificación adecuada del medio ambiente por lo que puede traer beneficios a la atmósfera urbana ya que las especies de árboles nativos deben tener uso preferente en detrimento de las especies exóticas, ya que son más adaptadas al ecosistema local y tienen mayor resistencia y adaptación a utilizar municipio urbano. Se concluyó que los beneficios que los elementos arbóreos aportan al microclima local son considerables y por lo tanto es necesario promover políticas públicas que entran en la planificación ambiental en el Plan Maestro de los municipios.

PALABRAS CLAVE: Urban florestación. Calidad de vida. Políticas públicas. 


\section{INTRODUÇÃO}

O conceito de arborização urbana diz respeito ao conjunto de áreas públicas e privadas com vegetação predominantemente arbórea ou em estado natural que uma cidade apresenta, incluindo as árvores de ruas e avenidas, parques públicos e demais áreas verdes (MILANO, 1988). O complexo vegetal urbano está ligado ao conceito físico territorial apresentado por GREY \& DENEKE (1978), compreende-se como arborização urbana o conjunto de terras, públicas e particulares com cobertura arbórea que uma cidade apresenta.

Os benefícios que a arborização urbana traz são importantes e numerosos. As áreas verdes têm papel fundamental na qualidade de vida da população e na redução dos impactos ambientais urbanos (SILVA, 2005; TOLEDO; SANTOS 2008), segundo Milano; Dalcin (2000), existem aspectos positivos das árvores nas cidades, os quais podem ser mensurados, avaliados e monitorados, caracterizando benefícios, e consequentemente, objetivos que passam a ser estabelecidos no planejamento, como estabilização do microclima, redução da poluição atmosférica e diminuição da poluição sonora, melhoria estética das cidades, ação sobre a saúde humana, benefícios sociais, econômicos e políticos.

O quadro ideal seria a implementação de ações que fomentem o aumento e manejo adequado da arborização urbana, associado ao desenvolvimento urbanístico de seu tecido urbano. Comumente, a arborização urbana e outros elementos convivem em desarmonia devido a ausência de planejamento tanto da arborização, quanto dos outros componentes desse espaço. (YAMAMOTO et. al. 2004)

O complexo vegetal urbano muitas vezes é relegado apenas as áreas verdes e obrigatórias que muitas cidades destinam em suas diretrizes municipais, são espaços muitas vezes residuais de loteamentos onde se priorizam a malha urbana em detrimento de áreas verdes. A cada dia se torna mais necessário a elaboração de um plano de arborização, baseado no estabelecimento de árvores bem distribuídas nas ruas, aproveitando os benefícios da planta para as necessidades humanas, na busca por qualidade de vida (MILLER, 1997).

O instrumento que normatizaria todo esse planejamento seria o Plano Diretor da Arborização Urbana. Segundo Araujo e Araujo (2011), um Plano Diretor da Arborização Urbana resulta de um planejamento detalhado, contendo as diretrizes, metas, ações e normas, para a realização de objetivos de curto e longo prazo.

Elementos arbóreos interagem de maneira positiva no microclima urbano, embora as condições sejam adversas para que desenvolvam seu ciclo de forma plena e correta, Lamas (1993, p. 106) pondera que: Do canteiro à árvore, ao jardim de bairro ou grande parque urbano, as estruturas verdes constituem também elementos identificáveis na estrutura urbana; caracterizam a imagem da cidade; têm a individualidade própria; desempenham funções precisas; são elementos de composição e do desenho urbano; servem para organizar, definir e conter espaços.

Assumindo caráter cada vez mais emergencial, a necessidade constante de implementação de planejamento ambiental acerca do tema, políticas públicas que tragam ao debate, a sociedade de um lado e poder público de outro, para que haja alinhamento de ações e que a floresta urbana seja incorporada de maneira mais produtiva na escala urbanística municipal. A visão de que não basta apenas ser relegada a espaços residuais que se tornarão áreas verdes, e sim que todo o complexo urbano seja objeto de ação deste plano de arborização urbana. 
Dessa forma, o objetivo do presente artigo é propor reflexões a respeito deste relevante tema, analisar a importância que o fomento de políticas públicas proporcionam ao setor. Propor um plano de ação direcionado a um Plano Diretor de Arborização Urbana (PDAU), na manutenção e manejo adequado das espécies arbóreas.

Para tanto, a metodologia utilizada será a de revisão bibliográfica por meio de livros, artigos e revistas científicas, relatórios técnicos de órgãos oficiais. "É a análise que vai permitir observar os componentes de um conjunto, perceber suas possíveis relações, ou seja, passar de uma ideia-chave para um conjunto de ideias mais específicas, passar à generalização e, finalmente, à crítica." (MARCONI, LAKATOS, 2010, p.27). Será realizado em conjunto o trabalho em campo: serão realizadas visitas as áreas urbanas onde os dados sobre os números de espécies arbóreas possam ser colhidos e analisados, verificando os impactos junto à arborização urbana. "É desenvolvida por meio das observações diretas das atividades do grupo estudado e de entrevistas com informantes para captar suas explicações e interpretações que ocorre no grupo." (GIL, 2009). Esse processo de coleta de dados tem como objetivo fornecer um inventário sobre a situação real e atual da arborização urbana para que análises mais corretas possam ser realizadas para compor o plano de ação do Plano Diretor da Arborização Urbana (PDAU).

\section{ARBORIZAÇÃO URBANA}

O aumento exponencial da malha urbana caminha conjuntamente com o desenvolvimento histórico do homem e o desenvolvimento econômico da sociedade como um todo. $O$ consequente e progressivo avanço do tecido urbano das cidades produziu a diminuição da cobertura arbórea nativa, ocasionando desequilíbrio no ecossistema local.

A arborização urbana necessita de um planejamento ambiental correto para que possa trazer benefícios para a ambiência urbana. A definição de arborização urbana se relaciona ao plano físico territorial apresentado por GREY \& DENEKE (1986), "compreende-se como arborização urbana o conjunto de terras, públicas e particulares com cobertura arbórea que uma cidade apresenta". No complexo urbano as espécies arbóreas nem sempre estão em quantidade ideal ou mesmo em condições de vida consideradas ideais. A importância e as funções da vegetação urbana estão relacionadas, dentro outros fatores, à paisagem, ao ambiente, onde atua nos microclimas urbanos, e contribui para melhorar a ambiência urbana e a percepção das pessoas (MASCARÓ, 2002). A ambiência urbana sinaliza características adversas para as árvores, diferentes das encontradas no ecossistema natural, consideradas ideais pois estão distantes das ações antrópicas impostas pelo homem.

As espécies nativas são as que reúnem melhores características para compor a floresta urbana, estão adaptadas ao clima local e com resistência maior que uma espécie exótica por exemplo. A biodiversidade das espécies nativas deve ser valorizada na arborização urbana de um município, facilitando um planejamento de plantio e manejo mais adequados. Cria-se também uma identidade e valorização da fauna local, reforçando o sentimento de pertencimento às raízes que uma população nutre por sua terra.

Espécies arbóreas que não são nativas podem trazer problemas ao equilíbrio pretendido, estas chamadas de espécies exóticas: "São aquelas que ocorrem numa área fora de seu limite natural historicamente conhecido, como resultado de dispersão acidental ou intencional através de atividades humanas" (INSTITUTO DE RECURSOS MUNDIAIS; UNIÃO MUNDIAL PARA A NATUREZA; PROGRAMA DAS NAÇÕES UNIDAS PARA O 
MEIO AMBIENTE, 1992). A população destas espécies exóticas passa a se tornar um problema grave quando as mesmas estabelecem e passam a ter uma população auto regenerativa e ocupam espaço das espécies nativas, gerando desequilíbrio nas relações ecológicas, segundo Grey e Deneke (1986), é aconselhável que as espécies de maior frequência não ultrapassem os $15 \%$ do total.

A arborização urbana traz vantagens que mitigam os efeitos negativos da diminuição do complexo vegetal, para isso é necessário estudo e planejamento, Pereira (1998) enfoca a necessidade de se fazer um planejamento cuidadoso para a implantação de projetos de vegetação em ambiente urbano, através da análise de todas as interfaces com os elementos construídos e seus diferentes usos, para isso é necessário que se estabeleça a preferência para utilizar-se de espécies arbóreas nativas e com boa adaptação ao uso urbano, evitando que espécies exóticas se proliferem e venham a comprometer o frágil equilíbrio ecológico que se pretende.

Incorporar árvores pode significar redução significativa da sobrecarga dos sistemas de drenagem de águas pluviais urbanas, melhorando, quando possível, a infiltração pelo solo, auxiliando inclusive na redução da velocidade de água das tempestades (TROWBRIDGE \& BASSUK, 2004). Segundo McPherson et al. (1997), os benefícios que os elementos arbóreos trazem para o microclima local são consideráveis, segundo ANDRADE (2003) o microclima reflete a influência de elementos urbanos e dos seus arranjos mais elementares (edifícios e suas partes constituintes, ruas e praças e pequenos jardins. Atuam no controle da umidade relativa do ar, mitigam os efeitos da variação de temperatura provenientes das ilhas de calor, produzem áreas de sombreamento, minimizam efeitos da poluição sonora, produzem composição estética e paisagística e atuam no sequestro do dióxido de carbono $\left(\mathrm{CO}_{2}\right)$. O termo "sequestro de carbono" teve seu conceito lançado no Protocolo de Kyoto, uma conferência de âmbito mundial realizado em 1997 e onde foi estabelecido critérios para comprometer os países industrializados a reduzirem a emissão dos Gases do Efeito Estufa (GEE). Deveriam adotar políticas e medidas de mitigação capazes de fazer com que seus níveis de emissão antrópica de GEE retornassem aos níveis de 1990 no máximo até o ano 2000 (MAY, LUSTOSA, VINHA 2003). Embora tenha ocorrido a negativa em assinar este acordo por parte de muitos países que, reconhecidamente, emitem altas taxas destes gases. O Protocolo trouxe como ponto relevante a discussão sobre o tema em âmbito mundial, além do alerta incisivo sobre os impactos causados e riscos para a sobrevivência humana. As emissões brasileiras anteriores de $\mathrm{CO} 2$ concentram-se em dois 17 setores: o primeiro, na queima de combustíveis fósseis, que libera por ano de 80 a 90 milhões de toneladas de carbono; e o segundo, na alteração do uso da terra, principalmente a substituição de florestas e savanas por agricultura e pastagem, que libera anualmente de 200 a 250 milhões de toneladas de carbono (NOBRE, 2004).

A preocupação mundial sobre a modificação do clima global, criou o interesse cada vez maior em árvores para ajudar a reduzir o nível de CO2 atmosférico (DWYER et al, 1992). A poluição ambiental destaca-se como um dos principais aspectos a ser discutido por pesquisadores, entidades governamentais e pela sociedade em geral (HORGNIES et. al., 2012).

A arborização urbana tem uma relação especial com a poluição atmosférica. Por um lado, ela gera benefícios para o ambiente e, consequentemente, para o homem. Porém, para desempenhar essa função a integridade das árvores é ameaçada. Para usufruirmos das 
vantagens de tal relação é necessário manter árvores nas cidades, mas em condições que permitam, no mínimo, a sobrevivência dessa vegetação. (FIRKOWSKI, 1990)

Em uma estimativa feita na cidade de Chicago apontou que o incremento de $10 \%$ na cobertura vegetal urbana pode reduzir a energia gasta com resfriamento em até US\$ 90 por ano por habitação, a Associação Americana de Engenheiros Florestais estima que cada árvore propicie uma oferta de serviços no valor de US\$ 273,00/indivíduo/ano. O panorama atual em nosso país aponta para índices poucos satisfatórios em termos de planejamento ambiental associado à arborização urbana.

Historicamente a reflexão sobre esta importância ainda é considerado recente, somente em 1985 aconteceu o primeiro ENCONTRO NACIONAL SOBRE ARBORIZAÇÃO URBANA, realizado em Porto Alegre - RS, marco histórico que simboliza o início da produção de planejamento acerca do tema. Porto Alegre tem seu pioneirismo reconhecido nacionalmente sendo um dos primeiros municípios a inserir esse planejamento em seu plano diretor municipal. Capitais como Curitiba e Goiânia também seguem a mesma linha e produziram seus respectivos planos de arborização urbana, reconhecidamente são cidades onde é notável que a arborização urbana é diferenciada e melhor planejada que a maioria dos municípios brasileiros. A escolha das espécies arbóreas mais indicadas para o plantio também seguem diretrizes consideradas adequadas para a inserção na malha urbana. Ainda outros parâmetros devem ser verificados, tais como; a largura da calçada, fiação elétrica, clima, solo e umidade da localidade são variáveis que se mostram importantes na avaliação e procedimentos de seleção da espécie botânica (SILVA, 2005).

O manejo correto das espécies também deve ser item fundamental no planejamento da arborização. Técnicas para poda e plantio devem ser passadas em forma de treinamento para as equipes responsáveis por esta ação, pois esse tipo de serviço se for executado de maneira errônea pode trazer sérias complicações no ciclo de vida das espécies, segundo Milano e Dalcin (2000), de algumas recomendações de manejo se fazem necessárias. As podas severas devem ser evitadas, pois causam apodrecimento da madeira, secamento da casca e do câmbio, prejuízos à estética da árvore, sendo ainda caras e ineficientes. Fomentar políticas públicas que insiram o planejamento ambiental no Plano Diretor é necessário. O desenvolvimento da malha urbana deve caminhar em harmonia com a arborização urbana. $O$ avanço do processo democrático no país, o aumento da capacidade organizativa da sociedade e o ingresso na cena política de novos atores sociais têm exigido um profundo repensar do Estado em relação ao Planejamento Ambiental dos projetos de desenvolvimento (CAVALCANTI, 2001). O caráter emergencial desta questão e os impactos causados coloca a sociedade sempre em posição de decisão e ação para estes questionamentos.

\section{CONSIDERAÇÕES FINAIS}

A arborização urbana ainda é um conceito pouco valorizado em nosso país, parte pela premissa de que não temos educação ambiental em nossos sistema de ensino. Grande maioria da população não tem o conhecimento básico da potencialidade que os elementos arbóreos proporcionam para a ambiência urbana, de modo apenas intuitivo, conseguem elencar algumas vantagens que a floresta urbana reflete em sua convivência diária, em seus respectivos municípios.

O poder público é responsável direto e com maior poder de decisão a respeito deste tema. Em muitos casos pelo sistema político vigente em nosso país, onde profissionais com conhecimento técnico e teórico não 
estão incorporados nas Secretarias responsáveis pelo ordenamento urbanístico e ambiental do município, em grande parte estão sendo comandadas por pessoas sem a menor capacitação técnica e conhecimento básico sobre o tema, exercendo a função trabalhista apenas pela força da indicação política. Com este tipo de posicionamento político torna-se difícil estabelecer progressos na melhoria urbanística de nossas cidades. Políticas públicas devem incentivar a reflexão do poder público e da população sobre a importância, da inserção de plano de arborização urbana, nas diretrizes municipais urbanísticas. Embora o Brasil apresente baixos índices de municípios que contemplem o Plano Diretor de Arborização Urbana (PDAU), é cada vez mais emergencial que a infraestrutura urbana incorpore de modo mais produtivo e racional o complexo urbano vegetal em sua concepção.

\section{REFERÊNCIAS:}

ANDRADE, H. Bioclima humano e temperatura do ar em Lisboa. Dissertação de Doutoramento em Geografia Física. Faculdade de Letras da Universidade de Lisboa, 2003.

ARAUJO, M.N.; ARAUJO, A.J. Arborização Urbana. Série de cadernos técnicos da Agenda Parlamentar. Conselho Regional de Engenharia, Arquitetura e Agronomia do Paraná - CREA, 2011.

CAVALCANTI, C. (org). Desenvolvimento e natureza: estudos para uma sociedade sustentável 3 ed. São Paulo: Cortez; Recife, PE: Fundação Joaquim Nabuco, 2001

DWYER, J.F., MCPHERSON E.G; SCHROEDER H.W; ROWNTREE R.W. Assessing the benefits and costs of the urban forest. Journal of Arboriculture. 18:227-234, 1992

FIRKOWSKI, C. Arborização urbana. ENCONTRO NACIONAL SOBRE ARBORIZAÇÃO URBANA 3. 1990. Curitiba, 1990.

HORGNIES, M.; DUBOIS-BRUGGER, I.; GARTNER, E.M. NOx de-pollution by hardened concrete and the influence of activated charcoal additions. Cement and Concrete Research, v.42, p.1348 - 1355, 2012.

IBGE - Instituto Brasileiro de Geografia e Estatística. Censo do Entorno. Disponível em:

http://www.ibge.gov.br/home/estatistica/populacao/censo2010/entorno/default_entorno.shtm

GIL, Antonio Carlos, 1946. Como elaborar projetos de pesquisa. 4 ed. - 12. Reimpr. - São Paulo: Atlas, 2009.

GREY, G. DENEKE, F. Urban forestry. 2.ed. New York: John Wiley, 1986.

LAMAS, J. M. R. G. Morfologia urbana e desenho da cidade. Lisboa: Fundação Calouste Gubenkian. Junta Nacional de Investigação Científica e Tecnológica, 1993.

MARCONI, Mariana de Andrade, LAKATOS, Eva Maria. Técnicas de pesquisa: planejamento e execução de pesquisas, amostragens e técnicas de pesquisa, elaboração, análise e interpretação de dados. -7 ed. - 3 . Reimpr. - São Paulo: Atlas, 2010. 


\section{ANAP Brasil

MAY, P. H.; LUSTOSA, M. C.; VINHA, V. da. (org.) Economia do meio ambiente. Rio de Janeiro: Elsevier, 2003.

MASCARÓ, Lucia Elvira Alicia Raff; MARCARÓ, Juan Luis. Vegetação urbana. Porto Alegre: UFRS, 2002.

MCPHERSON,G.;NOWAK, D.; HEISLER, G.; GRIMMOND, S.; SOUCH, C.; GRANT, R.; ROWNTREE, R. Quantify in urban for estructure, function and value: the Chicago Urban Forest Climate Project. Urban Ecosystems, v. , p. 49-61, 1997.

MILANO, M.S. Avaliação quali-quantitativa e manejo da arborização urbana: Exemplo de Maringá-PR. 1988. 120 F. Tese (Doutorado em Ciências Florestais) - Universidade Federal do Paraná, Curitiba - PR.

MILANO, M.S.; DALCIN E.C. Arborização de vias públicas. Rio de Janeiro: Light, 2000.

MILLER, R.W. Urban Forestry: Planning and Managing Urban Greenspaces. 2nd ed. New Jersey, Prentice Hall, 1997

NOBRE, C.A. O aquecimento global e o papel do Brasil. Revista Ciências Hoje. v..36. n.

211, dez. 2004. p.38-40.

PEREIRA, R. I. A vegetação e o espaço urbano. In: Paisagismo: a visão ambiental da paisagem. Curso. Brasília, p. 103-131, 1998

SILVA, L. F. da Situação da arborização Viária de espécies para os bairros Antônio Zanaga I e II, da Cidade de Americana/SP. 2005. 80f. Dissertação (Mestrado em Agronomia, área de concentração Fitotecnia) - Escola Superior de Agricultura "Luis de Queiroz", Universidade de São Paulo, Piracicaba, 2005.

TROWBRIDGE, P. J.; BASSUK, N. L. Trees in Urban Landscapes: site assessment, design and installation. Hoboken: Wiley \& Sons, 2004. 207p.

YAMAMOTO, M.A; SCHIMIDT, R.O.L; COUTO, H.T.Z; SILVA FILHO, D.F. Árvores Urbanas, Piracicaba,2004. 